\title{
Welcome to Flavour
}

\author{
Peter J Barham ${ }^{1,2}$ and Per Møller ${ }^{3^{*}}$
}

People who enjoy good food (and this, we are sure, includes most of us) live in exciting times as the quality and availability of foodstuffs has never been better across the developed world; chefs are taking advantage of the many opportunities to use novel ingredients to provide ever more enticing dining experiences and many also take advantage of the increased understanding of the science of taste and flavour that has emerged in the last decade or so.

In recent years, there has been an enormous increase in knowledge related to flavour, from the traditional fields of physics and chemistry [1], psychology and neuroscience [2] to, most recently, the new field of molecular gastronomy [3]. We hope that this new journal, Flavour, will provide a forum for scientists interested in flavour. We hope it will facilitate understanding of the ways flavour shapes our world - from pleasure to its broader effects on food choice, behaviour and health.

We take flavour to be the experience of eating food as mediated through all the senses. Thus, we welcome articles that deal with not only taste and aroma, but also chemesthesis, texture and all the senses as they relate to the perception of flavour.

We will publish interdisciplinary articles on flavour, its generation and perception, and its influence on behaviour and nutrition as well as articles on the psychophysical, psychological and chemical aspects of flavour including those which take brain imaging approaches.

We hope to make Flavour a journal not only for scientists, but also accessible to chefs and other food professionals who would not normally read the scientific literature. To that end we welcome articles from restaurants as well as those from traditional laboratories. As an open access journal, articles published in Flavour will be freely accessible online immediately after publication, allowing anyone with an interest in the field to have access to the most current research, review articles and opinion pieces.

\footnotetext{
* Correspondence: pem@life.ku.dk

${ }^{3}$ Department of Food Science, University of Copenhagen, Rolighedsvej 30, DK-1958, Frederiksberg, Denmark

Full list of author information is available at the end of the article
}

We hope that all papers published will be written in clear and precise language accessible to readers from all backgrounds. We aim to publish papers within the broad field of flavour from perspectives ranging from anthropology, philosophy and psychology to neuroscience, physics and chemistry. We hope an anthropologist can profit from reading a paper written by a physicist and vice versa. With this aim in mind, technical mathematical derivations and very elaborate materials and methods suited for the reproduction of experimental results should be given in appendices.

There are many challenges facing those interested in the general area of flavour; below we pose a few questions that we feel are well worth addressing and challenge you, our readers, to begin to answer some of them:

- Are there any relationships between the pleasure derived from eating and satiation?

- What makes some foods delicious and some not?

- What are the fundamental mechanisms by which we gain pleasure from the flavour of what we eat?

- What is satisfaction obtained from "flavour" and how can it be quantified?

- Can we develop precise concepts of complexity relevant for flavour:

$\circ$ physical/chemical concepts

$\circ$ perceived complexity - in psychological contexts and in relation to neural activities, for example, as measured by neuroimaging techniques

$\circ$ environmental concepts

- Behavioural choices in relation to flavour and food selection, from the perspectives of the customer, manufacturers and restaurateurs and a neuro-economic standpoint.

- Food pairing principles - which foods go well together and why? Do any of these principles transcend different culinary traditions and cultures? If so, what are the determinants and underlying mechanisms of such universality? 
- Can humans be addicted to foods? If so, is this a physical or a behavioural addiction?

- Can one transform a given food into a more healthy one without diminishing the hedonistic aspects?

- For example, can one use different aspects of flavour to make a food appear more "creamy"?

- Can we determine relationships between physical structure and (perceived) texture?

- Can new insights into the physics of the structure and manipulation of food allow us to develop new textures, or textures that change according to the environment or over time while being consumed?

- The inverse problem in cooking: from a perceptual and physical description of (the perfect) end result of a cooking process, can we describe the physical treatment of the raw materials that will result in a given (e.g. the optimal) end result?

In the first issue of Flavour we publish papers which fall within the realms of experimental psychology, chemistry and sensory science, on topics including the role of attention in flavour perception, how food aroma affects bite size, and seaweeds for umami in the new Nordic cuisine.

Flavour will accept research articles, review articles and book reviews as well as letters to the Editor, opinion pieces and methodology pieces. It is our hope that the journal will provoke a fierce debate and that it will develop into a truly interdisciplinary journal publishing contributions that cover the whole spectrum from the human sciences to the social sciences and the natural sciences.

We hope that you are excited by the scope of this new journal and that you will start to rise to some of the challenges we have posed above - we await your submission with eager anticipation.

\section{Author details}

${ }^{1}$ University of Bristol, H. H. Wills Physics Laboratory, Tyndall Avenue, Bristol, United Kingdom BS8 1TL. '2Department of Zoology, University of Cape Town, Rondebosch, 7701 Cape Town, South Africa. ${ }^{3}$ Department of Food Science, University of Copenhagen, Rolighedsvej 30, DK-1958, Frederiksberg, Denmark.

Received: 14 March 2012 Accepted: 21 March 2012 Published: 21 March 2012

\section{References}

1. Vega C, Ubbink J: Trends Food Sci Technol. 2008, 19:372-382.

2. Spence C: Psychologist. 2010, 23(9):720-723.

3. Barham P, Skibsted LH, Bredie WLP, Frøst MB, Møller Per, Risbo J, Snitkjær P, Mortensen LM: Chemical Reviews. 2010, 110(4):2313-2365.

doi:10.1186/2044-7248-1-1

Cite this article as: Barham and Møller: Welcome to Flavour. Flavour 2012 $1: 1$.

\section{Submit your next manuscript to BioMed Central and take full advantage of:}

- Convenient online submission

- Thorough peer review

- No space constraints or color figure charges

- Immediate publication on acceptance

- Inclusion in PubMed, CAS, Scopus and Google Scholar

- Research which is freely available for redistribution 